\title{
Determinants of malaria mortality among displaced people in Khartoum state, Sudan
}

\author{
I.E. Saeed ${ }^{1}$ and E.S. Ahmed ${ }^{2}$
}

محددات معدلات الوفيات الناجمة عن الملاريا باستخدام أسلوب الصفة التشريحية اللفظية بين النازحين في .لئ

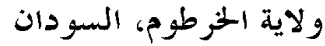

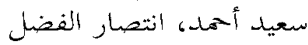

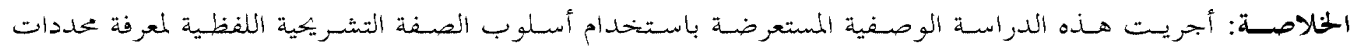

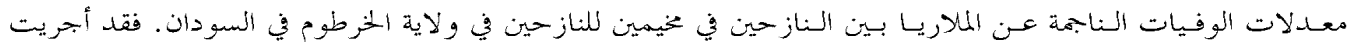

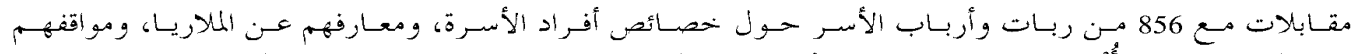

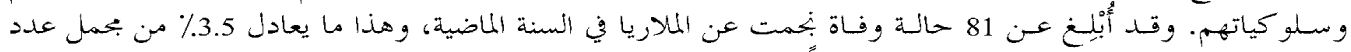

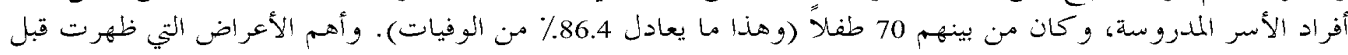

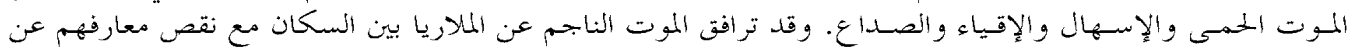

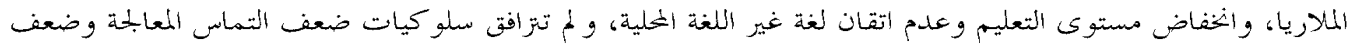

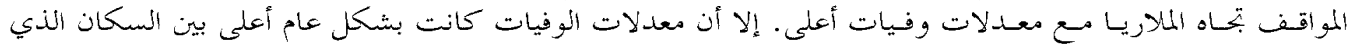

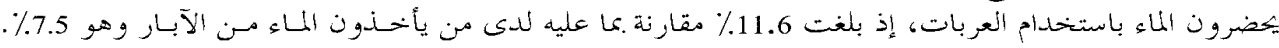

ABSTRACT To find the determinants of malaria mortality among displaced people, a cross-sectional descriptive study using verbal autopsy was carried out in 2 camps in Khartoum state, Sudan. The heads of 856 households were interviewed about household characteristics, and malaria knowledge, attitudes and behaviour. They reported 81 malaria deaths during the previous year, $3.5 \%$ of all household members; $70(86.4 \%)$ were children. Fever, diarrhoea, vomiting and headache were the most prevalent symptoms before death. Having a malaria death in the household was significantly associated with poor knowledge about malaria and, surprisingly, with better education. Poor treatment-seeking behaviour and poor attitudes towards malaria were not associated with higher mortality. However, mortality was significantly higher among households obtaining water by cart than from a well.

Déterminants de la mortalité palustre parmi les populations déplacées dans l'Etat de Khartoum (Soudan)

RESUME Afin d'identifier les déterminants de la mortalité palustre parmi les populations déplacées, une étude descriptive transversale utilisant l'autopsie verbale a été réalisée dans 2 camps de l'Etat de Khartoum (Soudan). Les chefs de famille de 856 ménages ont été interrogés sur les caractéristiques du ménage, ainsi que sur les connaissances, les attitudes et les comportements concernant le paludisme. Ils ont signalé 81 décès dus au paludisme au cours de l'année précédente, soit 3,5\% de l'ensemble des membres des ménages, dont $70(86,4 \%)$ étaient des enfants. Fièvre, diarrhée, vomissements et maux de tête étaient les symptômes les plus courants avant le décès. La survenue d'un décès dû au paludisme dans le ménage était associée de manière significative à une mauvaise connaissance du paludisme, une meilleure instruction et la pratique de la langue locale uniquement. Des comportements impropres pour chercher à se faire soigner et des attitudes négatives à l'égard du paludisme n'étaient pas associés à une plus forte mortalité. Toutefois, la mortalité était significativement plus élevée dans les ménages qui s'approvisionnent en eau par charrette plutôt que d'un puits.

${ }^{1}$ Centre for Science and Technology, Ahfad University for Women, Omdurman, Sudan.

${ }^{2}$ Department of Microbiology and Parasitology, College of Medicine, University of Juba, Juba, Sudan.

المجلة الصحية لشرق المتوسط، منظمة الصحة العالمية، المجلد التاسع، العدد ع، بr..r. 


\section{Introduction}

The most serious indication of the impact of a disease in any community is, obviously, the mortality rate. In many countries the cause of death is not routinely registered, and thus estimating the mortality due to diseases such as malaria can be difficult. In rural Africa, for example, unregistered home deaths may reach as high as 90\% [1]. Worldwide, deaths due to malaria range from 1.5 to 2.7 million, predominantly in children below 5 years of age and pregnant women [2]. In tropical Africa, malaria is responsible for about 1 million deaths and just over 200 million episodes of clinical disease [3]. In sub-Saharan Africa, where more than $90 \%$ of deaths occur, it is estimated that about $5 \%$ of children die from the disease before reaching the age of 5 years. Malaria has been shown to be a major cause of death among refugees and displaced people [4-6].

The effect of population movements on the incidence of malaria has been shown in a previous study [7]. In Sudan, malaria accounts for $25.7 \%$ of total hospital admissions and $15.9 \%$ of total deaths [8]. Furthermore, population movements, together with the spread of Plasmodium falciparum resistant strains, have further aggravated the problem [9]. At present, there is little information available about mortality from malaria in Sudan especially among displaced populations. Moreover, health service facilities lack mortality records. The present study was therefore conducted to estimate the malaria mortality rate among displaced people (based on a verbal autopsy method) and to determine the factors associated with malaria mortality in displaced people around Khartoum state.

\section{Methods}

A cross-sectional descriptive study was carried out during the period November 2001 to December 2002. Stratified systematic random sampling was used to select a representative sample of households from 2 camps of displaced people: Jabal Awlia and Cartoon Kassala. In each household, the head of the household was interviewed about sociodemographic factors and household characteristics and practices. Questions were asked about knowledge, attitudes and practices concerning malaria and about treatment-seeking behaviour. Respondents were asked if there had been any malaria deaths among the family members during the previous year and what symptoms the deceased had suffered. Full details of the methods can be found in an earlier paper from the same survey [10].

\section{Results}

A total of 856 household heads were interviewed, 272 from Jabal Awlia and 584 from Cartoon Kassala camp. Their sociodemographic characteristics and their knowledge, attitudes and practices concerning malaria have been reported in our earlier paper analysing the determinants of suffering a malaria attack [10].

\section{Determinants of malaria mortality}

A total of 81 deaths due to malaria were reported by 856 heads of households, 70 (86.4\%) of these among children. The total number of household members was 2288, giving a reported malaria mortality rate of $3.5 \%$ among household members. Fever, diarrhoea, vomiting and headache were the most commonly reported symptoms before death. 
Out of 81 families with deaths due to malaria, $76.5 \%$ reported having a malaria attack in the family during the previous year. The percentage of malaria attacks among families with death due to malaria (76.5\%) was higher than among those not reporting deaths in their family (67.4\%).

The risk of having a malaria death in the household (by verbal autopsy) was significantly higher for participants living in Jabal Awlia, a 3-fold increased risk compared with those residing in Cartoon Kassala (adjusted OR $=3.10$, 95\% CI: 1.20-8.10) (Table 1). Unexpectedly, household heads who were literate were at a significantly higher risk of having a malaria death in the household (basic education: adjusted $\mathrm{OR}=2.01$, 95\%, CI: 1.13-3.57; secondary/higher education adjusted OR $=3.24$, 95\% CI: 1.60 6.54). There was an increased risk of suffering a death in the family among household heads speaking only the local Dinka language compared with Arabic (16.4\% versus $4.8 \%, P<0.01$ by $\chi^{2}$ analysis). There was a higher risk among those with no income compared with those spending $\leq 50 \%$ of income on food $(17.1 \%$ versus $9.1 \%, P<0.05$ by $\chi^{2}$ analysis). However, the odds ratios for these last 2 factors did not reach statistical significance.

There was a significantly higherfedge about malaria (adjusted OR $=1.85,95 \%$ CI: 1.09-3.14) (Table 2). Knowledge of the correct dose of chloroquine was $72.3 \%$ in families without a reported death during the previous year and this was significantly higher than the $61.7 \%$ in families with a malaria death $(P<0.05$, odds ratio $=1.60$, $95 \%$ CI: 1.00-1.50). Mortality of a household member was $8.4 \%$ for household heads with good treatment-seeking behaviour compared with $10.1 \%$ in those with bad treatment-seeking behaviour but the difference was not significant.
There was an increased risk of mortality among those using carts to get water (11.6\% versus $7.5 \%, P<0.05$ by $\chi^{2}$-analysis) but the odds ratio did not reach statistical significance (adjusted OR $=2.25,95 \%$ CI: 0.86-5.84).

\section{Discussion}

Accurate determination of the mortality rate from malaria is difficult in many parts of rural Africa where as many as $90 \%$ of deaths from the disease occur at home and are not registered formally [1]. Verbal autopsy has become an important enough tool for WHO and UNICEF to hold a consultation on its use to estimate overall and cause-specific mortality in infants and children [11]. The use of verbal autopsy in determining causes of deaths has been assessed by various authors [12-14].

This study was conducted in 2 groups of displaced people in Khartoum state. Out of 856 respondents interviewed 81 reported deaths due to malaria in their families during the previous year, a malaria mortality rate of 3.5\% among household members. This figure seems to be reasonable, as the health services reported a malaria prevalence greater than $20 \%$ in the previous year, and another study in the same year showed that $73 \%$ of health service attendees were infected (Saeed and Salim unpublished data). Limitations on the use of verbal autopsy as an epidemiological tool for estimation of malaria mortality has been shown in previous studies [15-18].

Our result showed a significant association between poor knowledge about malaria and malaria mortality. Hence, respondents with poor knowledge reported a higher mortality rate among household members. On the other hand, poor attitudes and prac-

المجلة الصحية لشرق المتوسط، منظمة الصحة العالمية، المجلد التاسع، العدد ع، بr... 


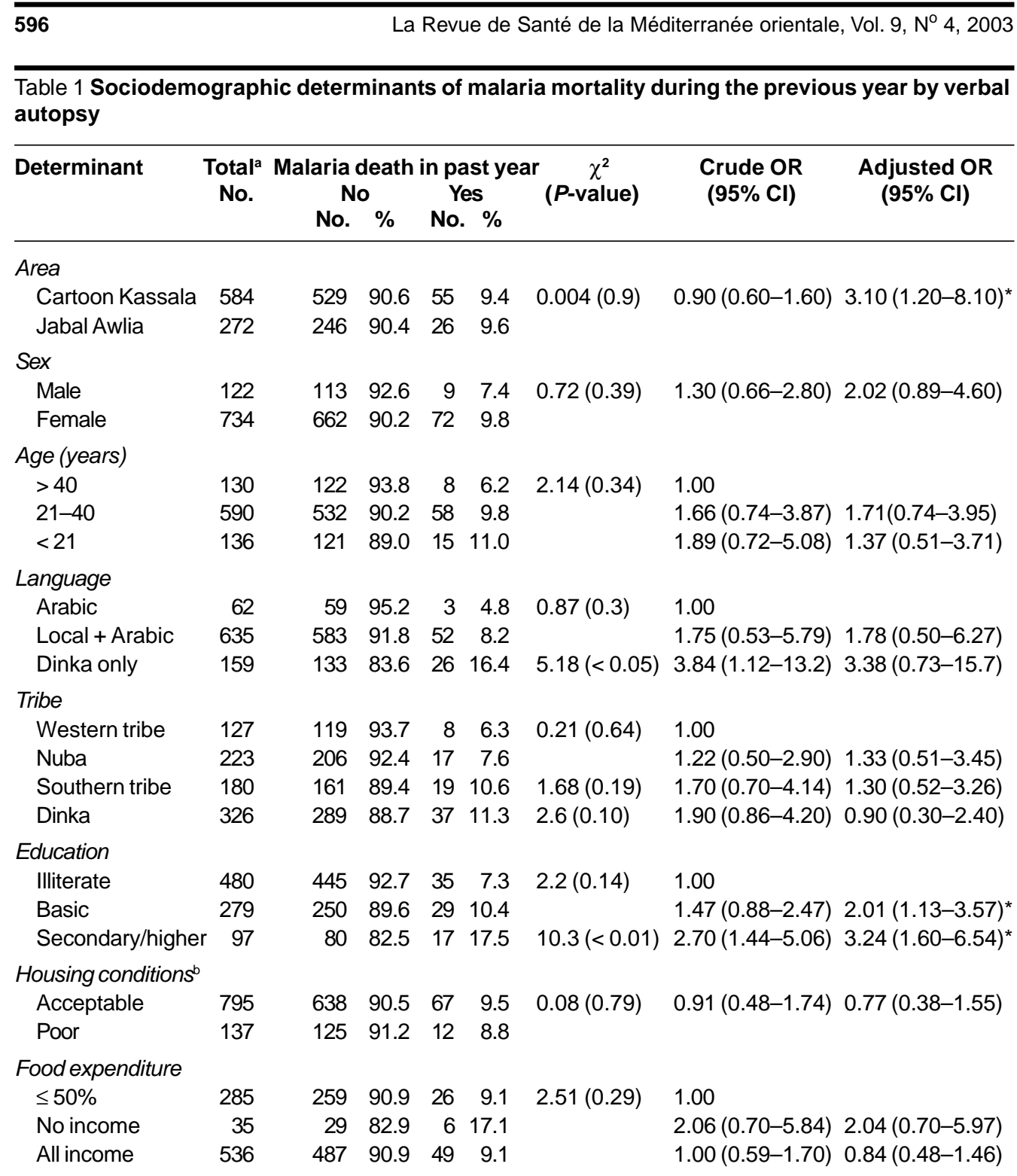

*P $<0.05$.

${ }^{a}$ Total number of heads of household interviewed.

${ }^{b}$ Presence of windows, surrounding walls, type of building, number of rooms.

tices towards malaria were not associated with higher mortality. A gap between knowledge and practice was clear in this study; a similar finding was reported in a previous study in Kenya [19]. In contrast, our report from the same survey showed no association between knowledge or attitudes towards malaria and the likelihood of suffering a malaria attack [10]. 


\begin{tabular}{|c|c|c|c|c|c|c|c|c|}
\hline \multicolumn{8}{|c|}{ Eastern Mediterranean Health Journal, Vol. 9, No. 4, 2003} & \multirow[b]{2}{*}{ s determinants } \\
\hline \multicolumn{8}{|c|}{$\begin{array}{l}\text { Table } 2 \text { Knowledge, attitudes and practices and treatment-seeking behaviour as determinants } \\
\text { of malaria mortality by verbal autopsy }\end{array}$} & \\
\hline \multirow[t]{2}{*}{ Determinant } & \multirow[t]{2}{*}{$\begin{array}{l}\text { Totala } \\
\text { No. }\end{array}$} & \multicolumn{4}{|c|}{$\begin{array}{l}\text { Malaria death in past year } \\
\text { No Yes }\end{array}$} & \multirow[t]{2}{*}{$\begin{array}{c}\chi^{2} \\
(P \text {-value })\end{array}$} & \multirow[t]{2}{*}{$\begin{array}{l}\text { Crude OR } \\
(95 \% \mathrm{CI})\end{array}$} & \multirow[t]{2}{*}{$\begin{array}{l}\text { Adjusted OR } \\
(95 \% \mathrm{Cl})\end{array}$} \\
\hline & & No. & $\%$ & No. & $\%$ & & & \\
\hline \multicolumn{9}{|l|}{ Knowledge } \\
\hline Poor & 370 & 325 & 87.8 & 45 & 12.2 & $5.5(<0.05)$ & $1.73(1.09-2.74)$ & $1.85(1.09-3.14)^{\star}$ \\
\hline Good & 486 & 450 & 92.6 & 36 & 7.4 & & & \\
\hline \multicolumn{9}{|l|}{$\begin{array}{l}\text { Attitudes and } \\
\text { practices }\end{array}$} \\
\hline Poor & 284 & 260 & 91.5 & 24 & 8.5 & $0.5(0.4)$ & $0.83(0.50-1.37)$ & $0.76(0.42-1.37)$ \\
\hline Good & 572 & 515 & 90.0 & 56 & 10.0 & & & \\
\hline \multicolumn{9}{|c|}{$\begin{array}{l}\text { Treatment-seeking } \\
\text { behaviour }\end{array}$} \\
\hline Poor & 533 & 479 & 89.9 & 54 & 10.1 & $0.73(0.39)$ & $1.24(0.76-2.00)$ & $1.44(0.81-2.57)$ \\
\hline Good & 323 & 296 & 91.6 & 27 & 8.4 & & & \\
\hline \multicolumn{9}{|l|}{ Water source } \\
\hline Well & 452 & 418 & 92.0 & 34 & 7.5 & $4.2(<0.05)$ & $1.61(1.01-2.57)$ & $2.25(0.86-5.84)$ \\
\hline Cart & 404 & 357 & 88.4 & 47 & 11.6 & & & \\
\hline \multicolumn{9}{|l|}{ Keeping water } \\
\hline No & 805 & 727 & 90.5 & 76 & 9.5 & $0.0(0.9)$ & $0.99(0.38-2.57)$ & $1.19(0.42-3.38)$ \\
\hline Yes & 53 & 48 & 90.6 & 5 & 9.4 & & & \\
\hline
\end{tabular}

${ }^{*} \mathrm{P}<0.05$.

aTotal number of heads of household interviewed.

The study revealed that death due to malaria was higher among family members of local language speakers than Arabic speakers ( $\chi^{2}$ analysis) perhaps because they depend primarily upon self-medication using traditional remedies and delay seeking treatment. This is consistent with our results from the same survey, which showed that risk of suffering a malaria attack was associated with speaking the local language [10]. The surprising finding that reported malaria mortality was higher among bettereducated families may be explained by the fact that they are more aware about the symptoms of malaria and may overestimate deaths due to malaria.

The study showed that reported malaria deaths were significantly higher (using $\chi^{2}$ analysis) among family members of households that obtain water by cart than those using a well. However, the odds ratio for this determinant did not reach statistical significance Although nearly half of the respondents used the cart water, only $2.1 \%$ reported keeping it for more than 1 week. We have already reported [10] that twothirds of respondents knew that stored water creates suitable breeding sites for mosquitoes. Our earlier report also showed a 4.7-fold increased risk of having a malaria attack in the previous year for those obtaining water from a cart rather than a well [10].

We have already reported that a high proportion of this sample delayed seeking treatment for malaria symptoms [10] and

المجلة الصحية لشرق المتوسط، منظمة الصحة العالمية، المجلد التاسع، العدد ع، ب...T 
this is in accordance with a previous study conducted in South Africa [20]. The practice of self-treatment was common among the displaced population in this study and this is likely to lead to delay in seeking treatment at health services and consequently a higher risk of malaria attacks [11] and death [21].

\section{Conclusions}

In conclusion, we should reiterate the conclusions of our previous study on malaria attacks in this sample of displaced people in Sudan [10]. Malaria morbidity and mortality can only be reduced if measures are taken to reduce illiteracy and poverty, educate the community in local languages, encourage early presentation with malaria symptoms to health facilities and improve water supplies to displaced people in camps.

\section{Acknowledgements}

We thank the National Malaria Control Administration, Sudan, the community health promoters at the health centres at the camps, the heads and members of households enrolled in this study for their collaboration. Our thanks are due to Dr Siddig Shahin, University of Khartoum for his help in analysing the data and Dr Bilgis Badri, Ahfad University for Women.

This investigation received technical and financial support from the joint WHO Eastern Mediterranean Region (EMRO), Division of Communicable Diseases (DCD) and the WHO Special Programme for Research and Training in Tropical Diseases (TDR): the EMRO/DCD/TDR Small Grants Scheme for Operational Research in Tropical and Communicable Diseases.

\section{References}

1. Greenwood B. Malaria mortality and morbidity in Africa. Bulletin of the World Health Organization, 1999, 77(8):617-8.

2. World Health Organization. World malaria situation in 1994. Weekly epidemiological record, 1997, 72:269-76.

3. Snow RW et al. Estimating mortality, morbidity and disability due to malaria among Africa's non-pregnant population. Bulletin of the World Health Organization, 1999, 77(8):624-40.

4. Toole MJ, Waldman R J. Prevention of excess mortality in refugee and displaced populations in developing countries. Journal of the American Medical Association, 1990, 263(24):3296-302.

5. Najera JA. Malaria control among refugees and displaced populations. Geneva, World Health Organization, 1996 (CTD/MAL/96.6).
6. Toole MJ, Waldman RJ. The public health aspects of complex emergencies and refugee situations. Annual review of public health, 1997, 18:283-312.

7. Breman JG, Campbell CC. Combating severe malaria in African children. Bulletin of the World Health Organization, 1988, 66:611-6.

8. Annual health statistical report. Khartoum, Sudan, National Health Information Centre, Federal Ministry of Health, 2001.

9. Guthmann JP et al. Field research, relief work and war: does chloroquine-resistant malaria occur in displaced populations of Southern Sudan? Tropical doctor, 1996, 26(2):89-90.

10. Saeed IE, Ahmed ES. Determinants of acquiring malaria among displaced people in Khartoum state, Sudan. East- 
ern Mediterranean health journal, 2003, 9:581-92.

11. Measurement of overall and cause-specific mortality in infants and children: memorandum a from WHO/ UNICEF meeting. Bulletin of the World Health Organization, 1994, 72(5):707-13.

12. Premji $Z$ et al. Community based studies on childhood mortality in a holoendemic area on Tanzania coast. Acta tropica, 1997, 63(2-3):101-9.

13. Barnish $\mathrm{G}$ et al. Malaria in rural area of Sierra Leone. I. Initial results. Annals of tropical medicine and parasitology, 1993, 87(2):125-36.

14. Korenromp EL et al. Measurements of trends in childhood malaria mortality in Africa: an assessment of progress towards targets based on verbal autopsy. Lancet infectious diseases, 2003, 3(6): 349-58.

15. Snow RW et al. Childhood death in Africa: uses and limitation of verbal autopsies. Lancet, 1992, 340:351-5.

16. Chandramohan $D$ et al. Verbal autopsies for adult deaths: issues in their develop- ment and validation. International journal of epidemiology, 1994, 23:213-22.

17. Reeves BC, Quigley M. A review of dataderived methods for assigning causes of death from verbal autopsy data. International journal of epidemiology, 1997, 76: 1080-9.

18. Todd JE et al. The limitations of verbal autopsy in a malaria-endemic region. Annals of tropical paediatrics, 1994, 14(1):31-6.

19. Brooker $\mathrm{S}$ et al. Situation analysis of malaria in school-aged children in Kenyawhat can be done? Parasitology today, 2000, 16:183-6.

20. Durrheim DN et al. Confidential inquiry into malaria deaths. Bulletin of the World Health Organization, 1999, 77:263-6.

21. Miguel $C$ et al. Patterns of treatment of malaria in Tayabas, The Philippines: implications for control. Tropical medicine and international health, 1998, 3:41321.

المجلة الصحية لشرق المتوسط، منظمة الصحة العالمية، المجلد التاسع، العدد ع، بr.ب 